\title{
Percutaneous coronary intervention in coronary total occlusions: In which patients?
}

\section{Intervencionismo coronario percutáneo en oclusiones coronarias totales: ¿en cuáles pacientes?}

\author{
Mario Araya ${ }^{a, b, *}$, Germán Armijo ${ }^{a}$ \\ a Hemodynamics Laboratory, Hospital San Juan de Dios, Santiago, Chile \\ b Clínica Alemana, Santiago, Chile
}

Received 1 April 2016; accepted 12 April 2016

\begin{abstract}
The treatment of a coronary chronic total occlusion is one of the main challenges of interventionist cardiology. Based on angiographs, the prevalence is 15 to $20 \%$. Revascularization is indicated less frequently due to a greater failure rate, greater exposure to radiation, high cost, and a greater frequency of complications. Therefore, only $35 \%$ of coronary chronic total occlusions are reportedly referred for revascularization, in which cases success is close to $80 \%$.

Uncertainties remain regarding the benefits of treatment, according to information obtained from observational studies $^{1}$. Patients are referred due to their symptoms, or because of significant ischemia on non-invasive tests. The proportion of asymptomatic individuals is close to $10 \%$. Finding a chronic total occlusion is one of the main reasons for referring a patient to coronary surgery.
\end{abstract}

\section{Fundamentals}

The indication for revascularization of a coronary chronic total occlusion is based on the severity of the symptoms, the

DOI of original article:

http://dx.doi.org/10.1016/j.rccar.2016.04.007

* Corresponding author.

E-mail address: marayah@alemana.cl (M. Araya).
Table 1 Potential benefits of revascularization of coronary chronic total occlusions ${ }^{3}$

Improved symptoms

Decreased need for myocardial revascularization surgery Decreased need for antianginal medications

Reduced mortality

Optimization of left ventricular function

Improved tolerance of acute coronary syndromes that might occur in the future

ischemic territory, and ventricular viability and function ${ }^{2}$. The operator's experience versus the angiographic complexity of the occlusion (objectifiable using clinical-angiographic scores such as the J-CTO score), should be analyzed ${ }^{3}$. Treatment is begun with optimal medical management and risk stratification. The greater the risk (e.g. a greater area of ischemia), the greater the benefit of angioplasty, and the more appropriate its indication.

Table 1 shows the benefits of percutaneous intervention.

In Joyal's meta-analysis ${ }^{4}$ of 13 observational studies, mortality at six years was lower in the group with 

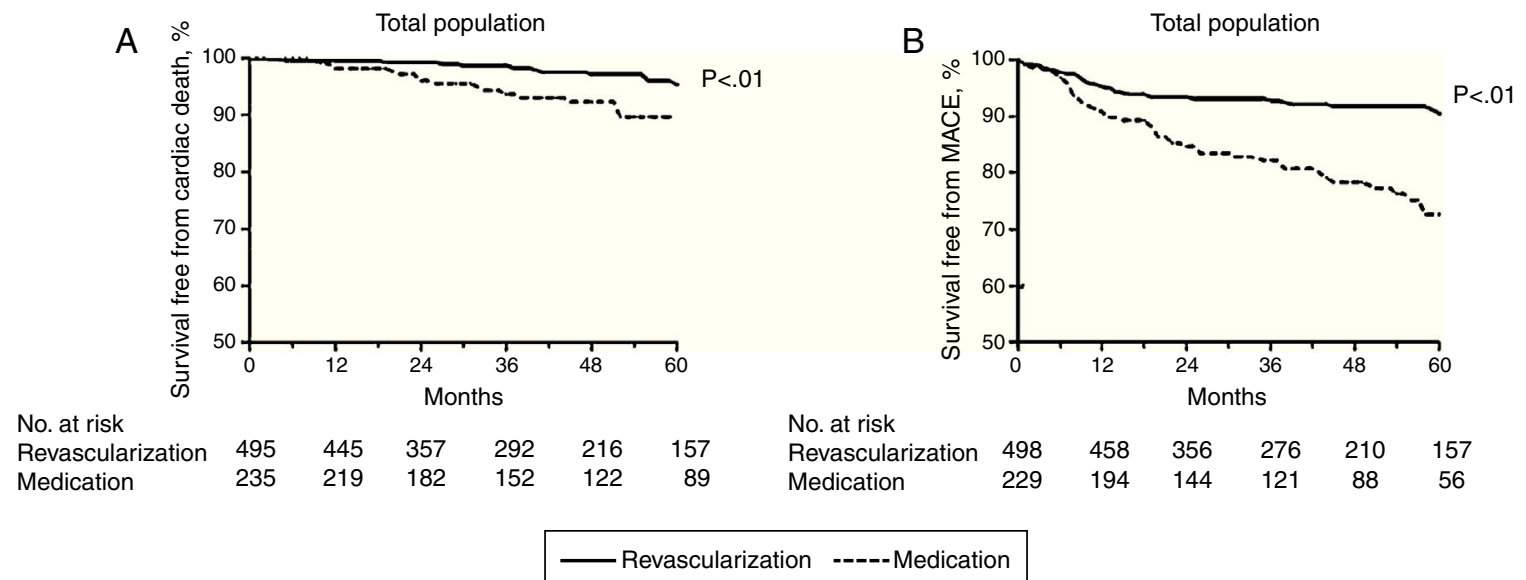

Figure 1 Kaplan-Meier curves for cardiovascular mortality (A) and MACE (B) in patients undergoing revascularization vs. medical treatment in the presence of collateral circulation.

successful rechanneling of the coronary chronic total occlusion, compared with the group that was not rechanneled $(14.3 \%$ vs. $17.5 \%$; OR 0,56$)$.

\section{Approach to the patient with coronary chronic total occlusion}

When coronary chronic total occlusion is found, the following factors are considered relevant.

\section{Presence and degree of ischemia}

Revascularization will be appropriate in patients with significant ischemia, even if they are asymptomatic, and/or have regional dysfunction of the left ventricle. Most cases of coronary chronic total occlusion will have significant ischemia, and it has been shown that angioplasty of a coronary chronic total occlusion significantly reduces ischemia, with a cut-off point of $12.5 \%$ ischemic burden as a predictor of benefit, and, lacking this, in ischemias lower than $6.25 \%^{5}$.

Typically, patients with coronary chronic total occlusion have collaterals to the distal segment, but these do not provide sufficient flow to the myocardium. Sachdeva et al., using FFR, showed that each coronary chronic total occlusion was hemodynamically significant, even with important collaterals ${ }^{6}$. A recent study comparing medical management of coronary chronic total occlusion with collaterals (Rentrop III) vs. percutaneous treatment, showed a lower incidence of cardiac death ${ }^{7}$ (HR:0.29; $\left.\mathrm{p}<0.01\right)$ and MACE (HR:0.32) in the revascularization group (Fig. 1).

\section{Presence of symptoms}

Successful revascularization of a coronary chronic total occlusion is associated with an improvement in symptoms. Benefits include decreased limitation of physical activity, fewer episodes of angina, and a better quality of life. A meta-analysis showed that successful rechanneling of a coronary chronic total occlusion produced greater symptom relief in long-term follow up, compared with the group where vessel rechanneling was unsuccessful ${ }^{4}$. In the
FACTOR study, Grantham reported significant improvement at one month using the Seattle Angina Questionnaire in treated symptomatic patients ${ }^{8}$.

\section{Possibility of success}

The success rate in coronary chronic total occlusion ranged from $50 \%$ to $75 \%$. Advances in techniques, new dedicated guide wires, microcatheters and greater operator experience have increased the success rate. The Euro CTO Club reports $83 \%$ success, and in Japan and groups in the USA with hybrid confrontation, rates close to $90 \%$ are reported. Against these figures, however, there is a greater rate of complications, especially coronary perforation (3\%), periprocedural infarction (2.4\%) and contrast-induced nephropathy (3\%). Mortality is between 0.2 and $1.3 \%$. The operator's learning curve and experience is a factor that should be considered.

\section{Coronary chronic total occlusion in the presence of multivessel disease}

Coronary chronic total occlusion is common in multivessel disease and determines the option of revascularization. In the Canadian Registry of coronary chronic occlusions ${ }^{9}$, multivessel disease was present in $3 / 4$ of patients, a finding associated with greater referral for surgery.

Furthermore, if percutaneous treatment is selected in this context and there is a chronic total occlusion, failed revascularization is frequent. There is current evidence to show that incomplete revascularization in multivessel disease treatment is a determining factor in a worse prognosis.

\section{Viability and ventricular dysfunction}

Patients with multivessel disease frequently present a history of infarction and left ventricular dysfunction with potentially recoverable territory. The diagnostic tools for seeking viability are crucial for evaluating the potential benefit of revascularization. In our experience, nuclear magnetic resonance is the method of choice since in its delayed 
contrast analysis the extent of necrosis in the myocardial wall thickness can be determined. Necrosis of less than $75 \%$ of the thickness could be benefited by a percutaneous revascularization, with the beneficial effect increasing as the percentage of necrosis decreases. A meta-analysis published in 2015 by Hoebers ${ }^{10}$ showed that following percutaneous rechanneling of a coronary chronic total increased $4.4 \%$ (95\% $\mathrm{Cl}$; 3.52-5.35, $\mathrm{p}<0.01$ ) compared to baseline. In addition, a decrease in end diastolic volume was reported.

\section{Revascularization of a coronary chronic total occlusion in post acute myocardial infarction patients}

Among acute myocardial infarction patients, approximately 40 to $60 \%$ have multivessel disease, and it is estimated that close to $10 \%$ have a coronary chronic total occlusion in a vessel unrelated to the infarction. Multivessel disease with a coronary chronic total occlusion is an independent predictor of mortality during infarction. The COREA-AMI study notes that patients who underwent a successful percutaneous rechanneling of the coronary chronic total occlusion (not responsible for the infarct) had a lower global mortality ( 16.7 vs. $32.3 \%)$ and MACE ( 21.9 vs. $55.2 \%)$ compared with the non-treated group ${ }^{11}$, which suggests the relevance of the treatment in this context.

\section{Conclusions}

Percutaneous interventionism of the coronary chronic total occlusion may provide significant benefits for the patient when it is clinically indicated and the procedure is appropriate. Patients should be treated according to their symptoms or evidence of ischemia, in viable territory, and not according to the operator's skills (risk of inappropriate angioplasty). The myocardium irrigated by a coronary chronic total occlusion will always be an ischemic zone, even in the presence of good collateral circulation. Extensive ischemia, coronary chronic total occlusion in the presence of multivessel disease, or acute myocardial infarction, is associated with a worse prognosis. Successful treatment is associated with fewer symptoms, better quality of life and optimization of ventricular function indices. Benefits have been reported with regard to cardiovascular mortality, although there are no definitive data, as yet ${ }^{12}$. Successful complete percutaneous revascularization should be the goal, a factor which should increase the number of treated coronary chronic total occlusion patients. The foregoing supports the idea of developing coronary chronic total occlusion programs with dedicated operators having more than 50 coronary chronic total occlusion procedures/year, as well as referral networks, in order to optimize patient selection, maximize success, and decrease possible complications.

\section{References}

1. Strauss BH, Shuvy M, Wijeysundera HC. Revascularization of Chronic Total Occlusions Time to Reconsider? JACC. 2014:64.

2. Shah PB. Management of coronary chronic total occlusion. Circulation. 2011;123:1780-4.

3. Morino Y, Abe M, Morimoto T, Muramatsu T, Ochiai M, Mitsudo K, et al. J-CTO Registry Investigators. Predicting successful guidewire crossing through chronic total occlusion of native coronary lesions within 30 minutes. The J-CTO (Multicenter CTO Registry in Japan) Score as a Difficulty Grading and Time Assessment Tool. J Am Coll Cardiol Intv. 2011;4:213-21.

4. Joyal D, Afilalo J, Rinfret S. Effectiveness of recanalization of chronic total occlusions: a systematic review and meta-analysis. Am Heart J. 2010;160:179-87.

5. Safley DM, Koshy S, Grantham JA, Bybee KA, House JA, Rutherford BD, et al. Changes in myocardial ischemic burden following percutaneous coronary intervention of Chronic total occlusions. Catheter Cardiovasc Interv. 2011;78:337-43.

6. Sachdeva R, Agrawal M, Flynn SE, Werner GS, Uretsky BF. The myocardium supplied by a chronic total occlusion is a per- sistently ischemic zone. Catheter Cardiovasc Interv. 2013;83:9-16.

7. Jang WJ, Yang JH, Choi SH, Song YB, Hahn JY, Gwon HC, et al. Long-term survival benefit of revascularization compared with medical therapy in patients with coronary chronic total occlusion and well-developed collateral circulation. JACC Cardiov Interv. 2015:8.

8. Grantham JA, Jones PG, Cannon L, Spertus JA. Quantifying the early health status benefits of successful chronic total occlusion recanalization: Results from the FlowCardia's Approach to Chronic Total Occlusion Recanalization (FACTOR) Trial. Circ Cardiovasc Qual Outcomes. 2010;3:284-90.

9. Fefer P, Knudtson ML, Cheema AN, Galbraith PD, Osherov AB, Strauss BH, et al. Current perspectives on coronary chronic total occlusions: the Canadian Multicenter Chronic Total Occlusions Registry. J Am Coll Cardiol. 2012;59:991-7.

10. Hoebers LP, Claessen BE, Elias J, Dangas GD, Mehran R, Henriques JP. Meta-analysis on the impact of percutaneous coronary intervention of chronic total occlusions on left ventricular func- tion and clinical outcome. Int J Cardiol. 2015;187: 90-6.

11. Choi IJ, Koh YS, Lim S, Choo EH, Seung KB, Kim PJ, et al. Impact of percutaneous coronary intervention for chronic total occlusion in non-infarct-related arteries in patients with acute myocardial infarction (From the COREA-AMI Registry). Am J Card. 2016;117:1039-46.

12. Lee PH, Lee SW, Park HS, Kang SH, Bae BJ, Park SJ, et al. Successful recanalization of native coronary chronic total occlusion is not associated with improved long-term survival. JACC Cardiovasc Interv. 2016;9:530-8. 